\title{
Potential Utilization of Pineapple Waste Streams for Polyhydroxyalkanoates (PHAs) Production via Batch Fermentation
}

\author{
Waranya SUWANNASING ${ }^{1)}$, Tsuyoshi IMAI' ${ }^{2)}$, Pakawadee KAEWKANNETRA ${ }^{3)}$ \\ 1) Graduate School of Khon Kaen University, Mittraphap Road, Mueang, Khon Kaen 40002, \\ Thailand \\ 2) Division of Environmental Science and Engineering, Graduate School of Science and \\ Engineering, Yamaguchi University, Ube 755-8611, Japan \\ 3) Department of Biotechnology, Faculty of Technology, Khon Kaen University, Mittraphap \\ Road, Mueang, Khon Kaen 40002, Thailand
}

\begin{abstract}
This study involves the production of a value-added product of polyhydroxyalkanoates (PHAs) from pineapple cannery wastes by isolated bacterial strain of Bacillus sp. SV13 via batch fermentation process. Two carbon sources, glucose and sucrose, were used to investigate the potential of PHAs production compared to when the agro-industrial waste was used. Batch fermentation was performed in a flask scale under controlled conditions: $37^{\circ} \mathrm{C}$, and $200 \mathrm{rpm}$ of agitation rate. The PHAs concentration $[\mathrm{g} / \mathrm{L}]$, biomass in the forms of dried cell weight (DCW) [g/L] and specific product yield $(Y p / x)$ were determined by two-way analysis of variance (two-way ANOVA). The results revealed that PHAs concentration, biomass, and $Y p / x$ obtained from pineapple waste were significantly greater than the results obtained from glucose and sucrose. The Fourier transform infrared spectroscopy (FTIR) and nuclear magnetic resonance spectroscopy (NMR) techniques were used to examine the chemical structure of PHAs. It was found that the extracted PHAs remarkably showed in the form of polyhydroxybutyrate (PHB).
\end{abstract}

Keywords: biopolymer, polyhydroxyalkanoates, waste treatment

\section{INTRODUCTION}

The first discovery of polyhydroxyalkanoates (PHAs), classified as poly (3)-hydroxybutyrate (P(3HB)), was found in Bacillus megaterium (Lemoigne, 1926). Typically, PHAs are produced and accumulated as an intracellular granule by prokaryotic microorganisms and plants to store as carbon and energy source (Choi and Lee, 1999; Steinbüchel and Lütke-Eversloh, 2003). The presence of excess carbon source, when other essential nutrients such as nitrogen, phosphorous, or sulfur are limiting, is suitable for PHAs synthesis (Anderson and Dawes, 1990). Several kinds of microorganisms, such as archaea, mostly by Gram-negative bacteria and Gram-positive bacteria, produce PHAs (Kim and Lenz, 2001; Reddy et al., 2003). Since Gram-negative bacteria have endotoxin or lipopolysaccharide (LPS) in the outer membrane, it usually induces a strong immunogenic reaction in humans. On the other hand, PHAs produced from Gram-positive bacteria such as Bacillus sp. have gained interest from researchers studying in the biomedical field (Chen and $\mathrm{Wu}, 2005)$.

Nowadays, the bio-based polymers such as starch derivatives, polylactic acid, cellulosic polymer, and PHAs are attracting attention due to their material properties. These bio-based polymers are interesting alternative materials to decrease the environmental impacts of petroleum-derived plastics, which have extremely slow degradation rate

Address correspondence to Pakawadee Kaewkannetra, Department of Biotechnology, Faculty of Technology, Khon Kaen University, E-mail: pakawadee.kku@gmail.com

Received May 23, 2014, Accepted March 20, 2015. 
(Flieger et al., 2003). The biopolymers known as PHAs are polyester of hydroxyalkanoic acid polymers. The properties of PHAs depend on the length of their monomers which influences polymer hydrophobicity, melting point, glass transition temperature, degree of crystallinity, tensile strength, and elongation at break (Anderson and Dawes, 1990). One of the highlights of PHAs properties is its biodegradability because it can be completely degraded in the environment. In addition, the biocompatibility of PHAs has attracted attentions from tissue engineers as a potential material for medical devices such as suture fasteners, bone plates and bone plating systems, slings, surgical mesh, repair patches, and adhesion barriers (Zhao et al., 2003; Dai et al., 2009). Especially, PHAs in the form of PHB is biocompatible with various cell lines, including osteoblastic, epithelial cell and ovine chondrocytes (Rivard et al., 1996; Nebe et al., 2001).

The challenge to PHAs replacing the usual petroleum-derived plastics is production costs, especially the large impact of the price of carbon source on biopolymer processing. Therefore, the approach to reduce the costs is to employ cheap carbon sources. Many studies were reported on the production of PHAs using cheap carbon source, waste and by-product such as lactose (Povolo et al., 2010), whey (Pantazaki et al., 2009), molasses (Albuquerque et al., 2007; Bengtsson et al., 2010), sweet sorghum (Tanamool et al., 2013), sugar cane (Suwannasing et al., 2011) palm oil (Baskaran et al., 2013), olive oil mill (González-López et al., 1996; Pozo et al., 2002), and glycerol (Cavalheiro et al., 2009).

Considering the feasibility of agro-industrial wastes such as sugar-based materials that could be potentially utilized for PHAs fermentation by bacteria, pineapple waste is an interesting carbon source for PHA production. Thailand is one of the major exporting countries of canned pineapple in the world. The processing of canned pineapple is shown in Fig. 1. During the process, the raw material is lost and waste is generated at about $50 \%(\mathrm{w} / \mathrm{w})$ of pineapple. Moreover, a major cost for cannery process is raw material which is about $36 \%$, implying the need to economise the cost. Previously, the use of pineapple wastes as substrates for the production of methane, ethanol, citric acid, and antioxidants (Chau and David, 1995; Nigam, 1999; Tanaka et al., 1999; Kumar et al., 2003) have been studied. Moreover, the wastes from pineapple have also been extracted and purified to obtain bromelain enzyme (Ketnawa et al., 2012).

Pineapple waste is rich with sugar and nutrients that can be utilized by bacteria. Therefore, this study aims to investigate the alternative method to deal with the problem of raw material loss and waste generation. The anticipated outcome is the reduction of production cost for pineapple cannery process. Moreover, this study projected a new carbon source for Gram-positive bacteria and a new product from pineapple waste that could be converted into PHAs biopolymer as an alternative value-added product. 


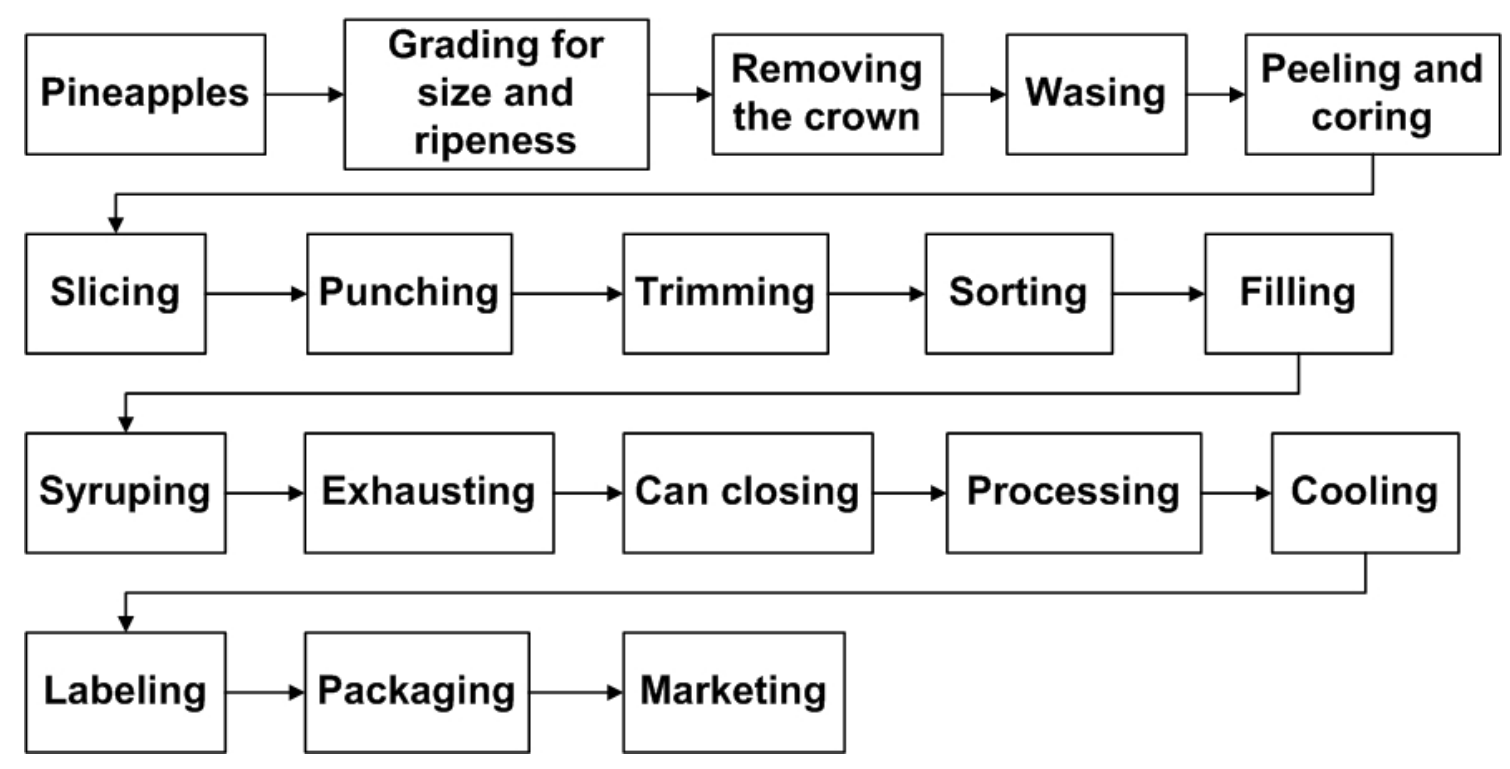

Fig. 1 - Process flow for pineapple slices in syrup (Food and Agriculture Organization of the United Nations, 1995).

\section{MATERIALSAND METHODS}

\section{Bacterial strain and media}

To investigate the production of PHAs by various carbon sources, the isolated Gram-positive bacterium, Bacillus sp. SV13 was employed as PHAs-producing bacterial strain. This strain was identified by $16 \mathrm{~S}$ rDNA technique and found that it was close to Bacillus cereus at $99 \%$ identity. The general characteristics reported in Bergey's manual indicated that this strain can also utilize various compounds such as glucose, sucrose, starch and citrates as sole carbon source (Breed et al., 1957). As a first step to enrich the inoculum, Bacillus sp. SV13 was grown in nutrient broth (consisting of $3 \mathrm{~g}$ beef extract and $5 \mathrm{~g}$ peptone) under aerobic condition with $200 \mathrm{rpm}$ of agitation rate at $37^{\circ} \mathrm{C}$ of cultivation temperature, and $10-12 \mathrm{~h}$ of cultivation time. Prior to use as inoculums, the cultivated nutrient broth was withdrawn to measure the optical density at the $600 \mathrm{~nm}$ absorbance which remarked at approximately $1.00 \pm 0.10$.

\section{Preparation of PHAs production medium}

The minimal medium was prepared following the procedure described by Grothe et al. (1999) and Atlas (2004). The composition in a litre contains $1.5 \mathrm{~g}\left(\mathrm{NH}_{4}\right)_{2} \mathrm{SO}_{4}, 1.8 \mathrm{~g}$ $\mathrm{Na}_{2} \mathrm{HPO}_{4}, 1.5 \mathrm{~g} \mathrm{~K}_{2} \mathrm{HPO}_{4}, 0.20 \mathrm{~g} \mathrm{MgSO}_{4} \cdot 7 \mathrm{H}_{2} \mathrm{O}$ and $1 \mathrm{~mL}$ trace element solution (A litre of trace element solution contained [g]: $0.18 \mathrm{ZnSO}_{4} \cdot 7 \mathrm{H}_{2} \mathrm{O}, 0.37 \mathrm{FeSO}_{4} \cdot 7 \mathrm{H}_{2} \mathrm{O}, 0.55$ $\mathrm{CoCl}_{2} \cdot 6 \mathrm{H}_{2} \mathrm{O}, 0.30 \mathrm{MnSO}_{4} \cdot 5 \mathrm{H}_{2} \mathrm{O}, 0.16 \mathrm{CuSO}_{4} \cdot 5 \mathrm{H}_{2} \mathrm{O}$, and $\left.0.12 \mathrm{Na}_{2} \mathrm{Mo} \cdot 2 \mathrm{H}_{2} \mathrm{O}\right)$. Three kinds of carbon sources: glucose, sucrose, and pineapple waste (prepared in the form of juice), were employed for PHAs production. To prevent a Maillard reaction, a carbon source was separated through sterilization at $121^{\circ} \mathrm{C}$ and 15 psi for $15 \mathrm{~min}$. After cooling, the mineral solution and carbon source solution were mixed. The initial total sugar concentration of three carbon sources was prepared at approximately $30 \mathrm{~g} / \mathrm{L}$. For pineapple waste, $227 \mathrm{~mL}$ of pineapple waste juice was added into the medium to adjust to $30 \mathrm{~g} / \mathrm{L}$ of total sugar. The initial $\mathrm{pH}$ was set at $6.5 \pm 0.5$. 


\section{Batch PHAs fermentation in flask}

The cultured seed inoculum in nutrient broth was inoculated $10 \%(\mathrm{v} / \mathrm{v})$ into $200 \mathrm{~mL}$ Erlenmeyer flask containing minimal medium. The fermentation was carried out under $37^{\circ} \mathrm{C}$ and $200 \mathrm{rpm}$. Samples were withdrawn at various times during $24-96 \mathrm{~h}$ to observe cell growth, biomass, PHAs concentration, and total sugar consumption. Finally, statistical analysis was analysed data using analysis of variance (ANOVA) and t-tests at 95\% confidence intervals by using Minitab 16 statistical software (Trial version).

\section{Analytical methods \\ Biomass}

The biomass was estimated in the form of dried cell weight (DCW) by gravimetric method (Hahn et al., 1995). The fermented broth was withdrawn $(10 \mathrm{~mL})$ and centrifuged $(\times 5,000 \mathrm{~g}$ for $15 \mathrm{~min})$. The supernatant was discharged and cell pellets were washed in distilled water, dried to achieve a constant weight at $105^{\circ} \mathrm{C}$, cooled down in desiccators and weighed.

\section{PHAs polymer recovery}

To obtain PHAs, 2 steps of disruption and extraction adopted by Hahn et al. (1995), were performed. Firstly, the centrifuged cell mass was incubated in sodium hypochlorite $(1: 1)$ at $37^{\circ} \mathrm{C}$ for $1 \mathrm{~h}$. Then, the polymer was extracted by hot chloroform at $50 \pm 5^{\circ} \mathrm{C}$ for $3 \mathrm{~h}$. Finally, it was evaporated at room temperature until the form was powder/sheet and then weighed as PHAs.

\section{Sugar consumption}

To examine the sugar content in pineapple waste, high performance liquid chromatography (HPLC) with a Vertical VertiSep GES NH2 column (Vertical Chromatography Co., Ltd., Nonthaburi, Thailand) and a refractive index detector was employed with the following chromatographic conditions: temperature at $40^{\circ} \mathrm{C}$; mobile phase acetonitrile $(75 \%)$ and water $(25 \%)$; mobile phase flow rate at $1.0 \mathrm{~mL} / \mathrm{min}$. The phenol-sulfuric acid method (Dubois et al., 1956) and 3,5-dinitrosalicylic acid (DNS) method (Miller, 1959) were used to determine the sugar concentration of minimal medium at the initial and at different points during fermentation for the period of $24-$ $96 \mathrm{~h}$.

\section{Bacterial growth}

To determine the bacterial growth, 2 variables (optical density and $\mathrm{pH}$ ), were measured after broth harvesting at various fermentation times. First, $1 \mathrm{~mL}$ of fermented broth was centrifuged $(\times 10,000 \mathrm{~g}$, for $10 \mathrm{~min})$. The supernatant was discharged and the pellet was re-suspended in distilled water. The turbidity of the re-suspended solution was then determined by measuring the absorbance at $600 \mathrm{~nm}$ wavelength. The acidity and alkalinity of broth were measured by $\mathrm{pH}$ meter.

\section{Characterisation of PHAs polymer}

To characterise the chemical structure of the recovered PHAs, the samples were analyzed by Fourier transform infrared spectroscopy (FTIR, Tensor 27, Bruker, MA, USA) in a range of $4,000-600 \mathrm{~cm}^{-1}$ to identify the functional group of polymer. Another technique called nuclear magnetic resonance spectroscopy (NMR, NMR-400 
$\mathrm{MHz}$ Spectrometer, Varian, CA, USA) was used to measure the chemical shifts of

${ }^{13} \mathrm{C}-\mathrm{NMR}$ at $400 \mathrm{MHz}$ and expressed in parts per million (ppm).

Nitrogen and phosphorous analyses

The standard methods for the examination of water and wastewater (APHA-AWWA-WEF, 2005) were used to determine the total nitrogen (TN) in the form of total Kjeldahl nitrogen (TKN) while total phosphorus (TP) was analyzed using stannous chloride method.

\section{RESULTS AND DISCUSSION}

\section{Characteristics and properties of pineapple waste}

The acidity-alkalinity test for pineapple waste showed a high acidic property at $\mathrm{pH}$ 3.7. Sugar content of pineapple waste measured by HPLC showed that it contained 47.77 $\mathrm{g} / \mathrm{L}$ glucose, $50.27 \mathrm{~g} / \mathrm{L}$ fructose, and $35.18 \mathrm{~g} / \mathrm{L}$ sucrose. Total sugar concentration was measured by phenol-sulfuric method and was about $133.22 \mathrm{~g} / \mathrm{L}$. The result indicated that pineapple waste has high sugar content that was sufficient as carbon source for PHAs-producing bacteria. Pineapple waste contained total nitrogen and phosphorous at about 980.0 and $47.5 \mathrm{mg} / \mathrm{L}$, respectively. Furthermore, the nutritional composition presented some minerals such as sodium $(\mathrm{Na})$, potassium $(\mathrm{K})$, calcium $(\mathrm{Ca})$, magnesium $(\mathrm{Mg})$, iron $(\mathrm{Fe})$, zinc $(\mathrm{Zn})$, and also vitamins which promoted the growth of bacteria (Smith, 1993). It is interesting to note that the composition and nutrients in pineapple wastes are feasible to utilize as carbon source for PHAs production.

\section{Bacterial growth and PHAs production in flask}

The growth of Bacillus sp. SV13 in Fig. 2 shows the clear trends of optical density and $\mathrm{pH}$. The optical density showed that with the three carbon sources, the bacterial growth was increased sharply in pineapple, especially during the first $48 \mathrm{~h}$ of fermentation. It implied that the bacteria grew very well, especially when pineapple juice was used as a carbon source. A decrease in $\mathrm{pH}$ implied that the metabolism occurred in the bacterial cells.

In Fig. 3, the PHAs concentration obtained, with pineapple as carbon source, was higher than those with glucose and sucrose. An approximately $0.40 \mathrm{~g} / \mathrm{L}$ of maximum PHAs concentration was reached with pineapple at around $48 \mathrm{~h}$ of fermentation, while the maximum PHAs concentration with sucrose and glucose were less than $0.10 \mathrm{~g} / \mathrm{L}$. For the DCW in various carbon sources, they showed quite a sharp increase within $24 \mathrm{~h}$ of fermentation followed by a slight increase onwards. Glucose and sucrose gave maximum DCW at $2 \mathrm{~g} / \mathrm{L}$, while pineapple juice achieved the maximum at around $4 \mathrm{~g} / \mathrm{L}$. Considering the specific product yield $(Y p / x)$ in three carbon sources under the same controlled conditions, it was found that the maximum PHAs production time was achieved at $48 \mathrm{~h}$. The conversion rate of DCW to PHAs in pineapple $(Y p / x, 0.15)$ was greater than in glucose $(Y p / x, 0.044)$ and sucrose $(Y p / x, 0.021)$. It implies that mixed sugar in pineapple could promote the growth of bacteria, both for DCW and PHAs production, while pure sugars, glucose and sucrose could not. 


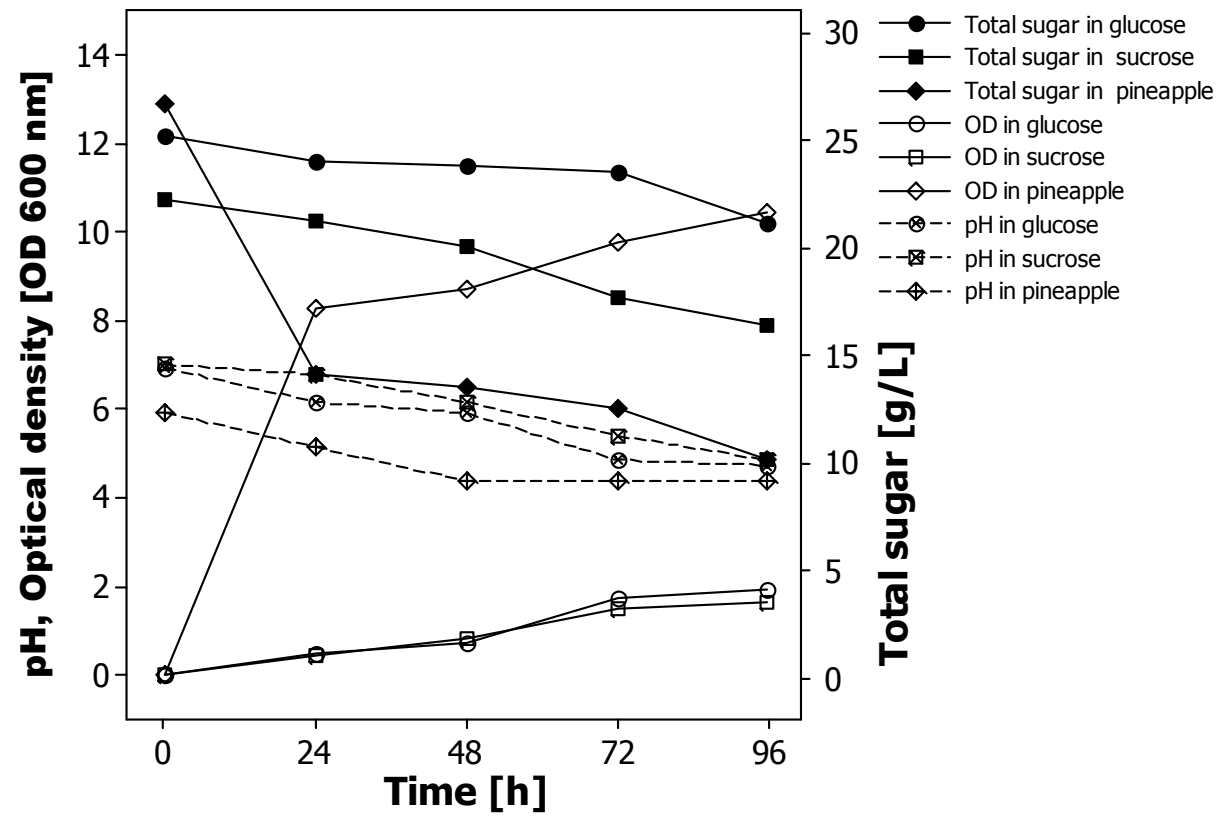

Fig. 2 - Growth profile of Bacillus sp. SV13 in minimal medium for PHAs production using various carbon sources (glucose, sucrose and pineapple).

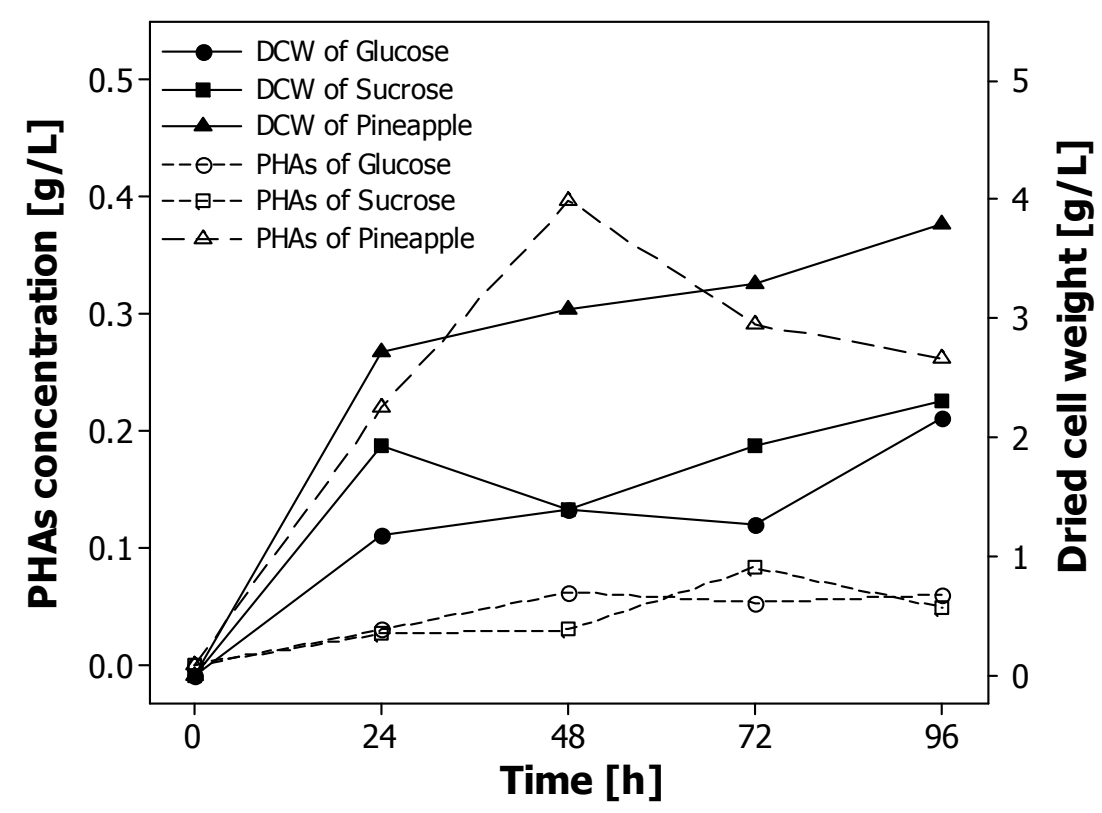

Fig. 3 - PHAs production profile of Bacillus sp. SV13 using various carbon sources (glucose, sucrose, and pineapple).

Table 1 shows a statistical analysis by two-way analysis of variance on PHAs concentration. Two factors, fermentation time and carbon sources, were analyzed. Different carbon sources had significant effect on PHAs concentration giving the values of $F(2,6)=33.7$ and $p$-value $<0.05$, while fermentation time showed no effect with $F(3,6)=1.43$ and $p$-value $>0.05$. 
Table 1 - Two-way analysis of variance (ANOVA) for PHAs concentration.

\begin{tabular}{|c|c|c|c|c|c|c|c|}
\hline Source of Variation & SS & df & MS & \multicolumn{2}{|c|}{$F$-calculate } & $P$-value & $F$-critical \\
\hline Fermentation time & 0.01418 & 3 & 0.00473 & \multicolumn{2}{|c|}{1.42725} & 0.32443 & 4.75706 \\
\hline Carbon sources & 0.22323 & 2 & 0.11161 & \multicolumn{2}{|c|}{33.70308} & 0.00055 & 5.14325 \\
\hline Error & 0.01987 & 6 & \multicolumn{3}{|c|}{0.00331} & & \\
\hline Total & 0.25728 & \multicolumn{2}{|l|}{11} & & & & \\
\hline Summary & Count & Sum & Average & Variance & Std. Dev & Low & High \\
\hline \multicolumn{8}{|l|}{ Fermentation time } \\
\hline $24 \mathrm{~h}$ & 3 & 0.27667 & 0.09222 & 0.01225 & 0.11067 & -0.01845 & 0.20289 \\
\hline $48 \mathrm{~h}$ & 3 & 0.48889 & 0.16296 & 0.04122 & 0.20303 & -0.04007 & 0.36600 \\
\hline $72 \mathrm{~h}$ & 3 & 0.42778 & 0.14259 & 0.01677 & 0.12949 & 0.01310 & 0.27209 \\
\hline $96 \mathrm{~h}$ & 3 & 0.55556 & 0.18519 & 0.05131 & 0.22652 & -0.04133 & 0.41170 \\
\hline \multicolumn{8}{|l|}{ Carbon sources } \\
\hline Glucose & 4 & 0.20556 & 0.05139 & 0.00022 & 0.01475 & 0.03664 & 0.06614 \\
\hline Sucrose & 4 & 0.18889 & 0.04722 & 0.00068 & 0.02599 & 0.02124 & 0.07321 \\
\hline Pineapple & 4 & 1.35444 & 0.33861 & 0.01046 & 0.10226 & 0.23635 & 0.44087 \\
\hline
\end{tabular}

The comparison of means using the Tukey's and Fisher's methods as shown in Table 2 clearly marked that the difference between glucose and sucrose was associated with a confidence interval by Tukey's method $(-0.126,0.117)$ and Fisher's method $(-0.102$, 0.094) that included zero. It indicated that the difference between glucose and sucrose was not statistically significant. While the confidence intervals by Tukey's method between the two other pairs: glucose and pineapple $(0.166,0.409)$, and sucrose and pineapple $(0.170,0.413)$, were revealed excluding zero. The result correlated with the confidence intervals calculated by Fisher's method for glucose and pineapple $(0.189$, $0.386)$ and sucrose and pineapple $(0.193,0.390))$. These results suggest that comparisons between glucose and pineapple and between sucrose and pineapple were significantly different, while that between glucose and sucrose was not.

The characterization of recovered PHAs, using pineapple as a carbon source, used FTIR spectroscopic technique to analyze the PHAs sample. In Fig. 4, the results revealed that the transmission bands from the FTIR spectrum of the PHAs sample related to the transmission bands of standard polyhydroxybutyrate (PHB). The carbonyl stretch $(\mathrm{C}=\mathrm{O})$ appeared in regions $1,720-1,721 \mathrm{~cm}^{-1}$ and $\mathrm{C}-\mathrm{H}$ stretch in the region $2,971 \mathrm{~cm}^{-1}$. The transmission region at about $1,320-1,210 \mathrm{~cm}^{-1}$ implied the functional group of $\mathrm{C}-\mathrm{O}$ stretch. Then, PHAs were determined and the functional groups of polymer structure were confirmed by NMR analysis. The ${ }^{13} \mathrm{C}-\mathrm{NMR}$ spectrum indicated that the recovery of PHAs presented in a form of PHB. The ${ }^{13} \mathrm{C}-\mathrm{NMR}$ showed the following chemical shifts: $19.732 \mathrm{ppm}$ corresponded to methyl group $\left(-\mathrm{CH}_{3}\right), 40.775 \mathrm{ppm}$ corresponded to methylene group $\left(-\mathrm{CH}_{2}-\right), 67.591 \mathrm{ppm}$ corresponded to methine group $(>\mathrm{CH}-)$ and 169.112 corresponded to carbonyl group $(\mathrm{C}=\mathrm{O})$. All chemical shifts correlated to a PHB standard (19.733, 40.767, 67.583 and 69.104, respectively) as shown in Fig. 5. The FTIR and NMR spectra related to the calculated chemical shifts supported the structure in the form of PHB, a polymer that belongs to the polyesters class (Doi et al., 1986; Galego et al., 2000; Oliveira et al., 2007; Jiang et al., 2008). 
Table 2 - Comparison of means using Tukey's and Fisher's methods.

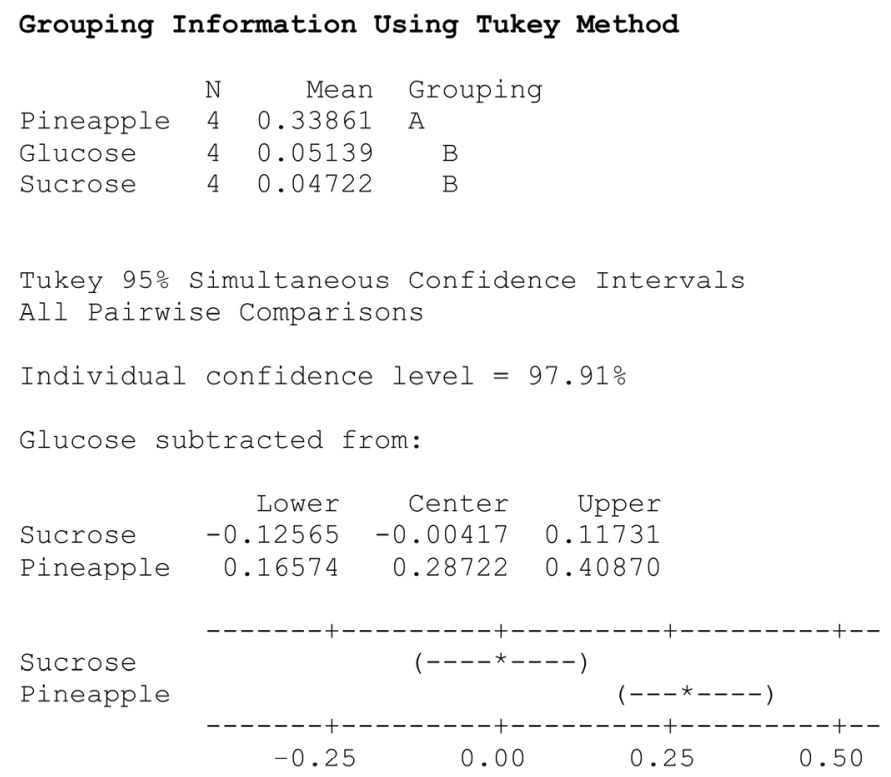

Sucrose subtracted from:

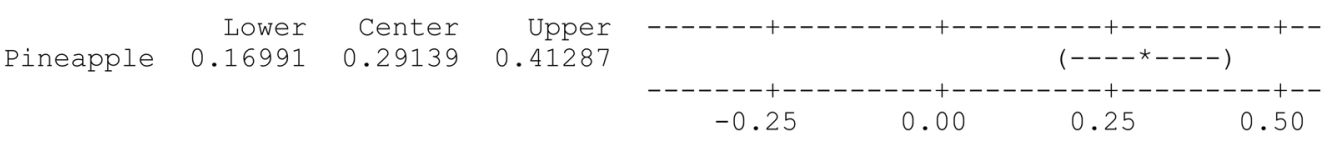

Grouping Information Using Fisher Method

$\begin{array}{llrl} & \text { N } & \text { Mean } & \text { Grouping } \\ \text { Pineapple } & 4 & 0.33861 & \text { A } \\ \text { Glucose } & 4 & 0.05139 & \text { B } \\ \text { Sucrose } & 4 & 0.04722 & \text { B }\end{array}$

Fisher 95\% Individual Confidence Intervals

All Pairwise Comparisons

Simultaneous confidence level $=88.66 \%$

Glucose subtracted from:

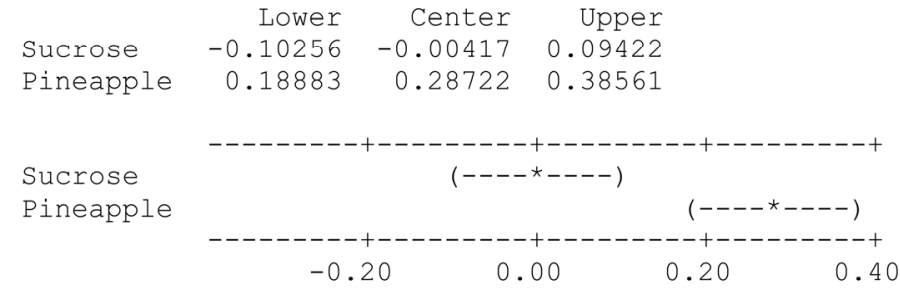

Sucrose subtracted from:

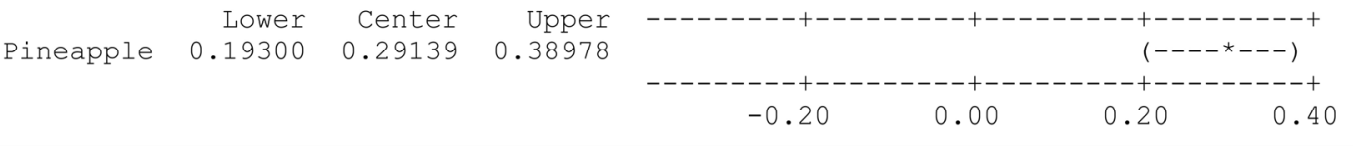


a) PHB standard

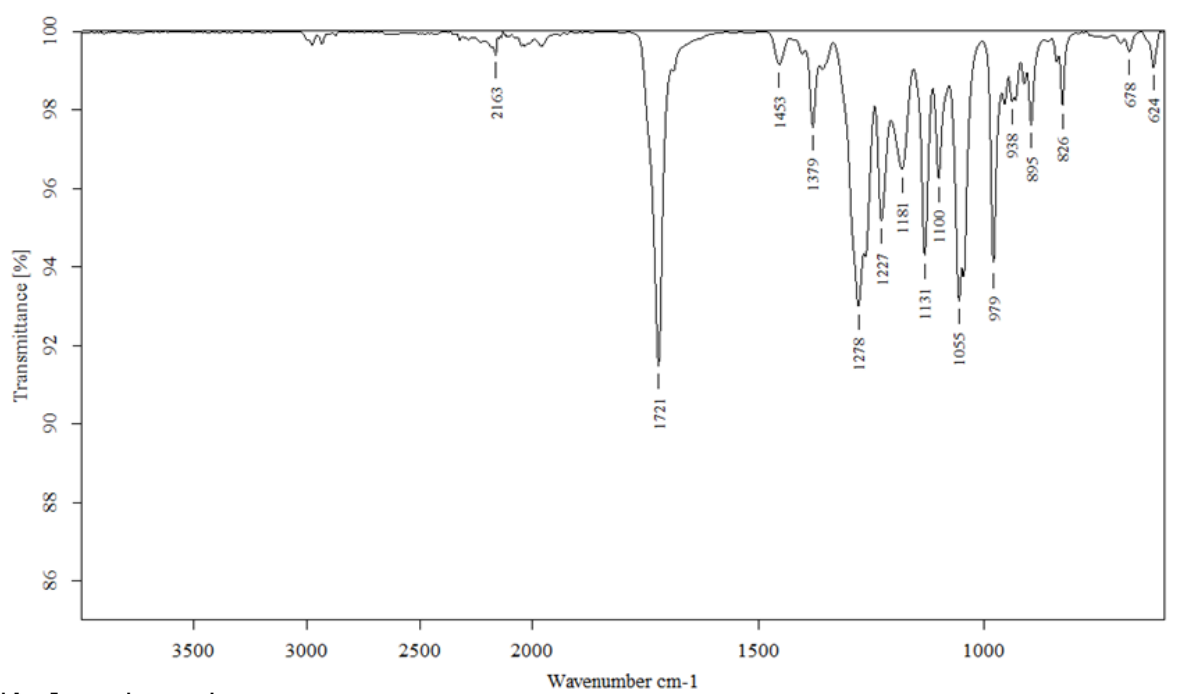

b) PHAs from pineapple

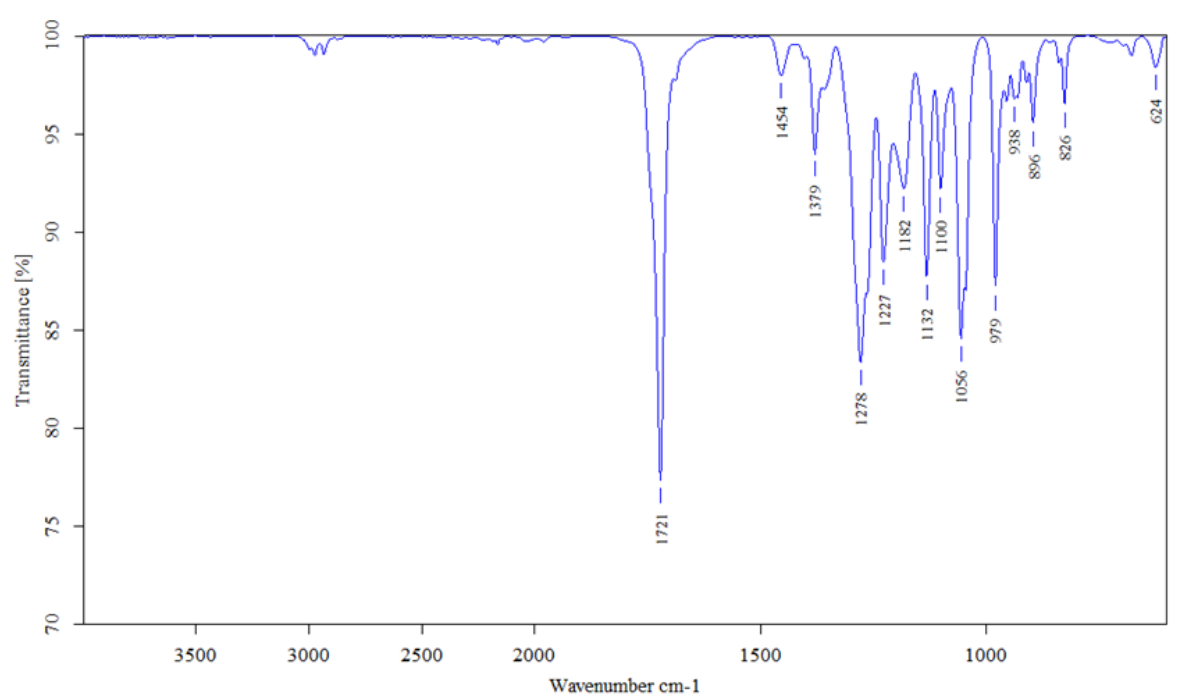

Fig. 4 - FTIR spectra of (a) poly-3-hydroxybutyrate (PHB) standard and (b) PHAs produced from pineapple wastes by Bacillus sp. SV13.

The results revealed that pineapple wastes can be used as carbon source by Bacillus sp. SV13 to produce PHAs granules better than those cases of pure sugars. Amino acids and some minerals in pineapple juice are necessary for bacterial growth. Therefore, it was clearly shown that Bacillus sp. SV13 could grow on pineapple juice better than glucose and sucrose. Interestingly, waste from pineapple canning process has potential to use as feedstock for PHAs production in large scale because pineapple canning process typically generates more than $50 \%$ wastes from pineapple and disposal is necessary. Therefore, it is very beneficial if pineapple wastes can be used as carbon source for PHAs production even though it is used for the manufacture of various products such as vinegar, alcohol, enzyme and paper. Further studies should be done to investigate the optimal concentration of pineapple wastes used to achieve the maximum PHAs concentration. 
a) PHB standard

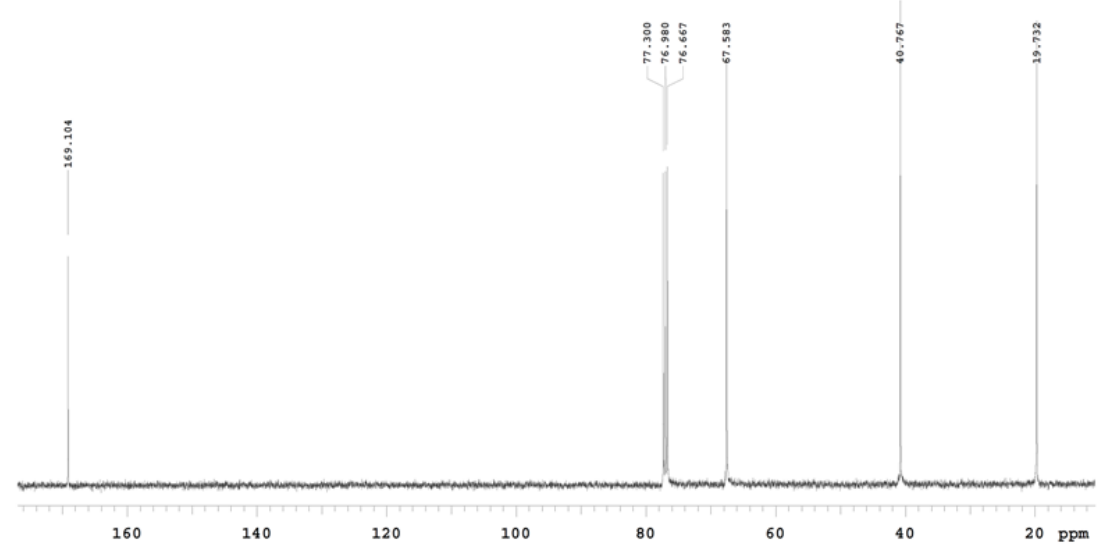

b) PHAs from pineapple

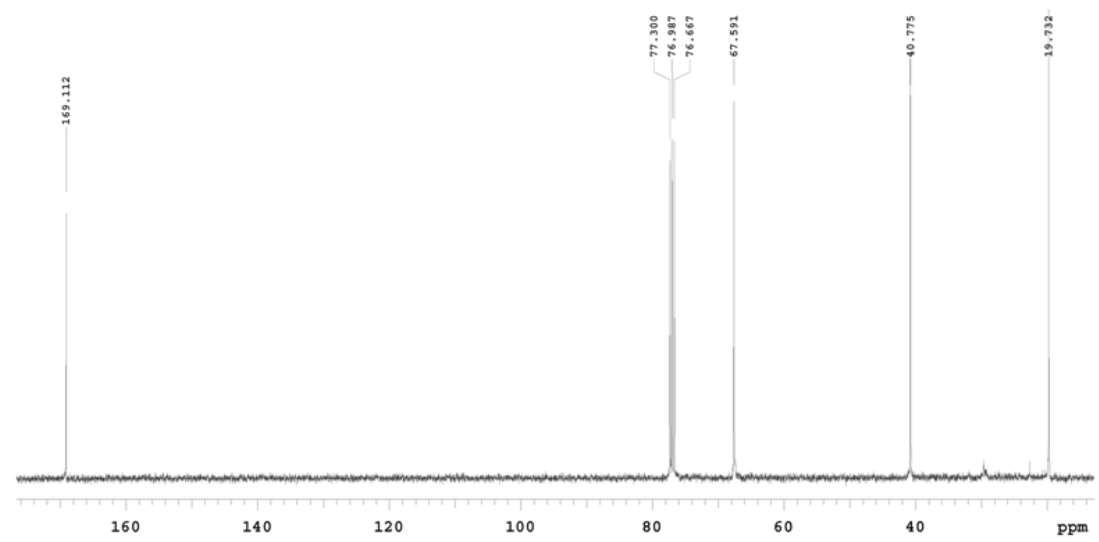

Fig. $5-{ }^{13} \mathrm{C}$-NMR spectra of (a) poly-3-hydroxybutyrate (PHB) standard and (b) PHAs produced from pineapple wastes by Bacillus sp. SV13.

\section{CONCLUSION}

The remarkable idea of utilizing pineapple waste, which is rich in sugar, is feasible to use for the production of PHAs via fermentation by Gram-positive bacteria in a small scale. The benefits included a new value-added product of biopolymer and an alternative method for waste treatment from pineapple waste. However, PHAs production from presented a low efficiency. Thus, the means of fermentation, aeration, agitation, temperature, and medium composition for large scale are needed for further investigation to enhance the potential of PHAs production.

\section{ACKNOWLEDGEMENTS}

This work was financially supported by Thailand Research Fund (TRF) for The Royal Golden Jubilee (RGJ) Fund (Grant no. PHD/0163/2553 for W. Suwannasing) and TRF (Contract no. DBG 5380013 for P. Kaewkannetra). The authors would like to sincerely thank the Division of Environmental Science and Engineering, Yamaguchi University, Japan, for collaborative research. 


\section{REFERENCES}

Atlas R. M. (2004) Handbook of microbiological media, 3rd ed. CRC Press, Florida, USA.

Albuquerque M. G. E., Eiroa M., Torres C., Nunes B. R. and Reis M. A. M. (2007) Strategies for the development of a side stream process for polyhydroxyalkanoate (PHA) production from sugar cane molasses. J. Biotechnol., 130(4), 411-421.

Anderson A. J. and Dawes E. A. (1990) Occurrence, metabolism, metabolic role, and industrial uses of bacterial polyhydroxyalkanoates. Microbiol. Rev., 54(4), 450-472.

APHA-AWWA-WEF (2005) Standard methods for the examination of water and wastewater, 21st ed. American Public Health Association/American Water Works Association/Water Environment Federation, Washington D. C., USA.

Baskaran M., Hashim R., Sudesh K., Sulaiman O., Hiziroglu S., Arai T. and Kosugi A. (2013) Influence of steam treatment on the properties of particleboard made from oil palm trunk with addition of polyhydroxyalkanoates. Ind. Crops Prod., 51, 334-341.

Bengtsson S., Pisco A. R., Reis M. A. M. and Lemos P. C. (2010) Production of polyhydroxyalkanoates from fermented sugar cane molasses by a mixed culture enriched in glycogen accumulating organisms. J. Biotechnol., 145(3), 253-263.

Breed R. S., Murray E. G. D. and Smith N. R. (1957) Bergey's manual of determinative bacteriology, 7th ed. Williams \& Wilkins Co., Baltimore, USA.

Cavalheiro J. M. B. T., de Almeida M. C. M. D., Grandfils C. and da Fonseca M. M. R. (2009) Poly (3-hydroxybutyrate) production by Cupriavidus necator using waste glycerol. Process Biochem., 44(5), 509-515.

Chau T. and David A. M. (1995) Pineapple waste - a novel substrate for citric acid production by solid state fermentation. Biotechnol. Lett, 17(10), 1107-1110.

Chen G. Q. and $\mathrm{Wu}$ Q. (2005) The application of polyhydroxyalkanoates as tissue engineering materials. Biomater., 26(33), 6565-6578.

Choi J. and Lee S. Y. (1999) Factors affecting the economics of polyhydroxyalkanoate production by bacterial fermentation. Appl. Microbiol. Biotechnol., 5(1), 13-21.

Dai Z. W., Zou X. H. and Chen G. Q. (2009) Poly (3-hydroxybutyrateco-3-hydroxyhexanoate) as an injectable implant system for prevention of post-surgical tissue adhesion. Biomater, 30(17), 3075-3083.

Doi Y., Nakamura Y., Kunioka M. and Soga K. (1986) ${ }^{1} \mathrm{H}$ and ${ }^{13} \mathrm{C}$ NMR analysis of poly ( $\beta$-hydroxybutyrate) isolated from Bacillus megaterium. Macromol., 19(4), 1274-1276.

Dubois M., Gilles K. A., Hamilton J. K., Rebers P. A. and Smith F. (1956) Colorimetric method for determination of sugars and related substances. Anal. Chem., 28(3), 350-356.

Flieger M., Kantorova M., Prell A., Rezaka T. and Votruba J. (2003) Biodegradable plastic from renewable source. Folia Microbiol., 48(1), 27-44.

Food and Agriculture Organization of the United Nations (1995) Fruit and vegetable processing. FAO Agricultural Services Bulletin No.119, Food and Agriculture Organization of the United Nations, Rome, Italy.

Galego N., Rozsa C., Sánchez R. and Tomáz J. S. (2000) Characterization and application of ( $\beta$-hydroxyalkanoates) family as composite biomaterials. Polym. Test., 19(5), 485-492.

González-López J., Pozo C., Martínez-Toledo M. V., Rodelas B. and Salmeron V. (1996) Production of polyhydroxyalkanoates by Azotobacter chroococcum H23 in wastewater from olive oil mills (alpechín). Int. Biodeterior. Biodegrad., 38(3-4), 
271-276.

Grothe E., Young M. M. and Chisti Y. (1999) Fermentation optimization for the production of Poly ( $\beta$-hydroxybutyric acid) microbial thermoplastic. Enzyme Microb. Technol., 25(1-2), 132-141.

Hahn S. K., Chang Y. K. and Lee S. Y. (1995) Recovery and characterization of poly (3-hydroxybutyric acid) synthesized in Alcaligenus eutrophus and recombinant Escherichia coli. Appl. Environ. Microbiol., 61(1), 34-39.

Jiang Y., Song X., Gong L., Li P., Dai C. and Shao W. (2008) High poly ( $\beta$-hydroxybutyrate) production by Pseudomonas fluorescens A2a5 from inexpensive substrates. Enzyme Microb. Technol., 42(2), 167-172.

Ketnawa S., Chaiwut P. and Rawdkuen S. (2012) Pineapple wastes: A potential source for bromelain extraction. Food Bioprod. Process., 90(3), 385-391.

Kim Y. B. and Lenz R. W. (2001) Polyesters from microorganisms. Adv. Biochem. Eng./Biotechnol., 71, 51-79.

Kumar D., Jain V. K., Shanker G. and Srivastava A. (2003) Utilisation of fruits waste for citric acid production by solid state fermentation. Process Biochem., 38(12), 1725-1729.

Lemoigne M. (1926) Produits de déshydration et de polymerisation de l'acide $\beta$-oxybutyrique. Bull. Soc. Chim. Biol., 8, 770-782.

Miller G. L. (1959) Use of dinitrosalicily acid reagent for determination of reducing sugar. Anal. Chem., 31(3), 426-428.

Nebe B., Forster C., Pommerenke H., Fulda G., Behrend D., Bernewski U., Schmitz K. P. and Rychly J. (2001) Structural alterations of adhesion mediating components in cells cultured on poly beta-hydroxybutyric acid. Biomater., 22(17), 2425-2434.

Nigam J. N. (1999) Continuous ethanol production from pineapple cannery waste. $J$. Biotechnol., 72(3), 197-202.

Oliveira F. C., Dias M. L., Castiho L. R. and Freire D. M. G. (2007) Characterization of poly (3-hydroxybutyrate) produced by Cupriavidus necator in solid-state fermentation. Bioresour. Technol., 98(3), 633-638.

Pantazaki A. A., Papaneophytou C. P., Pritsa A. G., Liakopoulou-Kyriakides M. and Kyriakidis D. A. (2009) Production of polyhydroxyalkanoates from whey by Thermus thermophilus HB8. Process Biochem., 44(8), 847-853.

Povolo S., Toffano P., Basaglia M. and Casella S. (2010) Polyhydroxyalkanoates production by engineered Cupriavidus necator from waste material containing lactose. Bioresour. Technol., 101(20), 7902-7907.

Pozo C., Martínez-Toledo M. V., Rodelas B. and González-López J. (2002) Effects of culture conditions on the production of polyhydroxyalkanoates by Azotobacter chroococcum $\mathrm{H} 23$ in media containing a high concentration of alpechín (wastewater from olive oil mills) as primary carbon source. J. Biotechnol., 97(2), 125-131.

Reddy C. S. K., Ghai R., Rashmi and Kalia V. C. (2003) Polyhydroxyalkanoates: an overview. Bioresour. Technol., 87(2), 137-146.

Rivard C. H., Chaput C., Rhalmi S. and Selmani A. (1996) Bio-absorbable synthetic polyesters and tissue regeneration. Ann. Chir., 50(8), 651-658.

Smith L. G. (1993) Pineapples. In: Encyclopedia of Food Sciences and Nutrition, R. Marcrae, R. K. Robinson and M. J. Sadler (eds), Butter and Tanned Ltd., UK, pp.3580-3604.

Steinbüchel A. and Lütke-Eversloh T. (2003) Metabolic engineering and pathway construction for biotechnological production of relevant polyhydroxyalkanoates in 
microorganisms. Biochem. Eng. J., 16(2), 81-96.

Suwannasing W., Mooamart S. and Kaewkannetra P. (2011) Yields of polyhydroxyalkanoates (PHAs) during batch fermentation of sugar cane juice by Alcaligenes latus and Alcaligenes eutrophus. J. Life Sci., 5, 960-966.

Tanaka K., Hilary Z. D. and Ishizaki A. (1999) Investigation of the utility of pineapple juice and pineapple waste material as low-cost substrate for ethanol fermentation by Zymomonas mobilis. J. Biosci. Bioeng., 87(5), 642-646.

Tanamool V., Imai T., Danvirutai P. and Kaewkannetra P. (2013) An alternative approach to the fermentation of sweet sorghum juice into biopolymer of poly- $\beta$-hydroxyalkanoates (PHAs) by newly isolated, Bacillus aryabhattai PKV01. Biotechnol. Bioprocess Eng., 18(1), 65-74.

Zhao K., Deng Y., Chen J. C. and Chen G. Q. (2003) Polyhydroxyalkanoate (PHA) scaffolds with good mechanical properties and biocompatibility. Biomater, 24(6), 1041-1045. 